\title{
Young Musicians for Heritage Project: Can a music-based Heritage Project have a positive effect on Well-being?
}

\author{
Carola Boehm and Ornette D Clennon
}

\begin{abstract}
This paper examines the intrinsic potential for well-being outcomes in a heritagerelated music project. We look at how creative activities that are embedded in a community can serve to enhance the cohesion and well-being of communities through the work of its youth groups. The paper also examines the important roles of partnership working and peer mentoring and how they need the time and resources to be nurtured in order to ensure sustainability and self empowerment as long term legacies of arts based community well-being initiatives.
\end{abstract}

Key words: arts, music, well-being, health, heritage, young people

\section{Introduction}

The Young Musicians for Heritage Project was initially set up by the Contemporary Arts Department at Manchester Metropolitan University to facilitate the exploration of Crewe's heritage by young people using music and music technology. However, it soon became apparent that the workshops needed to address the well-being of the young people as well as the creative and participatory aims of the project. We found that our project very soon located it self in the growing field of arts for health, which is informed by theories of well-being that suggest in different ways that participation in creative activities enhances life experiences. Elsewhere in the university we discovered two large complex projects where they explicitly investigated the impact of participation in arts activities on health and well-being, the research process itself contained creative methods. These activities included film, theatre, collage making, clapping and laughter processes and bookmaking (Sixsmith and Kagan, 2005; Kilroy et al.). However, in order to draw out our well-being outcomes, our project had to rely on a loose (uncoded) form of grounded theory methodology, (Corbin \& Strauss, 1990) to make sense of the enormous volume of data that was collected from the sessions over the course of the project. We feel that this project is very much the beginning of a methodology that combines arts and creative methods with social science research (Kagan and Duggan, 2011; Lawthom et al., 2011).

As well as being a music and heritage project Young Musicians for Heritage Project very much came to represent:

... people working together to express their needs, their hopes, their visions [...] About people being active and creative citizens and having fun together [...] being good for the health, well-being and self respect of individuals and the community (Angus, 1999:17). 
We found that although the well-being outcomes were initially co incidental to our principal creative aims they were crucial to the project because they allowed the creative activities to flourish. This meant that we had to continue to work closely with our principal partners to adjust the aims of the project so that they included an awareness and focus on well-being as well as the creative activities. We saw first hand that community arts for health can be about improving health and well-being in its widest sense and are often focused on individual development, as we conducted many 'on the fly' one to one sessions. We also grew to appreciate that the Arts can also offer innovative and effective approaches for tackling social exclusion and strengthening communities (Policy Action Team 10, 1999; New Opportunities Fund, 2006) and therefore be relevant to national and local programmes to reduce health inequalities (Department of Health, 2003). However, in writing this paper we found that the evidence base proving effectiveness remains small despite strong anecdotal evidence and a strong rationale (Hamilton et al., 2003). We feel that this is because activities of this nature are new and that there are also challenges in finding and using suitable evaluation methods that can represent individual and community change whilst tracking creative and participatory processes (Angus, 1999).

This paper reports on the evaluation of a recent community-based music project run in Crewe, Cheshire. The broad aim of the programme was to explore the heritage and history of Crewe using music and music technology. It involved a large number of music workshops that targeted disadvantaged communities.

The paper starts by providing a brief review of the literature on community arts for health.

\section{Community arts for health}

Anecdotal evidence suggests that participation in community arts can often have a direct effect on an individual's health and well-being through enhancing their understanding and expression or through developing the necessary skills to enable the adoption of healthy behaviours (Matarasso, 1997; Angus, 1999; Health Development Agency, 2000). Matarasso (1997) discovered 50 types of social impact resulting from participation in art, including improvements in health status. The survey of 243 adults and 270 children participating in arts projects found that 52 per cent of adults said that the felt better or healthier since their involvement.

In a review of community-based arts projects that The Health Development Agency (2000) carried out in England, it results, based on staff observations reported an impact on mental health where 91 per cent of projects reported an increase in the self esteem of its participants whilst 82 per cent saw an increase in confidence. Some projects also reported a reduction in anxiety and social isolation whilst other projects reported educational outcomes around the development of language, social and creative skills.

Everitt and Hamilton's (2003) systematic evaluation of five major long-term community-based arts for health projects also found good evidence of the impact on mental health in relation to reducing social isolation and improving self-esteem and 
confidence. Arts activities seemed to enable the development of emotional literacy, which was considered important for good mental health and for the development of strong relationships. Another evaluation of an arts for health programme by Smith, (2001) reported that community arts approaches seemed to be successful in creating healthy discussion and expression within groups. Some of the arts projects using group work in community settings saw intermediate outcomes of improved health information or improved environments.

In addition to promoting the health of individuals, community arts can be used to address some of the wider issues around health such as access to services, education and skills, employment, culture, and the physical/social environment. In their review, Newman et al., (2003) looked at the evidence on the social impact of art. Although only eight studies were of high enough quality to be included in the review, the authors concluded that there was evidence to support art as having a very positive impact in four areas:

1. Personal change (e.g. increased confidence)

2. Social change (including greater understanding of cultures and sense of community)

3. Economic change

4. Educational change

These findings are also supported by the Social Exclusion Unit's review of Arts and Sport (Policy Action Team 10, 1999), which reported evidence that communityfocused arts and sports programmes impacted on four broad areas:

1. Health

2. Crime

3. Employment

4. Education

Arts for health and well-being can be used to strengthen communities through promoting social cohesion and community networks (White and Robson, 2003). Individual and community health outcomes are perceived as inherently linked (Matarasso, 1997; Green and Tones, 2003), and the Health Development Agency (2000) has acknowledged the contribution of art to the building of social capital in communities. Studies of community arts in regeneration projects report that the arts often have an important impact on individual development and community cohesion in addition to environmental and economic aspects of regeneration (Landry and Matarasso, 1996; Central Research Unit Scottish Executive, 2000, Goodlad et al., 2002). It is also suggested that the arts can be particularly effective within areas of disadvantage and can attract and engage young people and other groups who might be otherwise marginalised (Kay, 2000).

The literature seems to point towards the most effective approaches to delivering community arts for health, as being methods that are community-centred, flexible, encourage participation, and those that are based on strong partnership working (Matarasso, 1997; Kay, 2000; Health Development Agency, 2000; Everitt and Hamilton, 2003). A national survey found that the main obstacles for projects were short-term or limited funding, lack of time, insufficient resources and poor quality 
venues (Health Development Agency, 2000). Challenges to bringing together creative approaches and mainstream health activities can also exist (Tones and Green, 1999; Smith, 2001).

In summary, there is evidence to support that using arts in community settings can enhance health and well-being. In a majority of the studies, participants and practitioners saw short-term benefits in terms of individual or community development. However, long-term health benefits are more difficult to measure and correlation is a problem (Goodlad et al., 2002, Newman et al., 2003). Since the field of community arts for health is diverse, there seems to scope for further studies that can show the impact of initiatives and also illustrate best practice in this area.

This paper will present the findings from a recent evaluation of a community-based music programme in Crewe, Cheshire, UK. The project involved significant work with two community groups. The following section will describe the background to the programme before going on to outline the evaluation methods. The paper will then present the main findings of the evaluation and discusses the limitations of the research. We will then discuss the implications on practice within the community arts for well-being field.

The purpose of the paper is twofold:

1. To report on the main findings from the evaluation and to locate the wellbeing outcomes from both the project and from the wider literature; and

2. To identify and discuss some of the implications for practice arising from the findings, such as development of local partnerships, approaches for reaching marginalised communities and the contribution of arts to well-being goals.

\section{Young Musicians for Heritage Project}

The main purpose of the Young Musicians for Heritage project was to encourage young adults to develop their own distinctive and creative engagement with their local heritage, mediated through musical, media and music-technological activities. In 2010 the Department of Contemporary Arts (DCA) at MMU Cheshire in collaboration with a local social enterprise company (Wishing Well), a heritage centre (Crewe Heritage Centre) and Cheshire East Council was successful in applying for a £23,500 grant from the Young Roots Heritage Lottery. The result of this project was the formation of a larger socially cohesive learning community motivated by the subject area of music. The project was a good example of how academia and social enterprises can play a vital part in allowing transformational partnerships to emerge based on creative practice. We achieved this by helping to create MMU community learning outposts where we were more visible and accessible to the local communities. Learners at different levels were involved in this project, and this allowed different stakeholder and different target audience to benefit in various ways.

Our model of involving different levels of learners that make up a cohesive "learning community" with an interest-focus around music \& digital media has allowed a longterm partnership to be established between community and university. The recurrent 
re-invigoration through the entrances of new students and new young people gives the project on the one hand a never-ending enthusiasm to explore all things music, but on the other hand allows longer learning to be supported through the apprenticeship and Gold Awards Scheme, providing at the same time spontaneity of individuals groups, and sustainability across longer time-scales.

In detail, the project involved:

- over 100 young people (11 to 25 yrs) from Crewe and Manchester

- 4 young people (18 to 25 yrs) have successfully completed Gold Arts Awards, 1 has successfully gained entry into MMU, 2 are preparing for university interviews

- 2 young people (11 to 15 yrs) have successfully completed Bronze Arts Awards

- 12 Contemporary Arts Students involved in the project as mentors

- Activities are supported by research of the academic department. Publications published and in preparation are: a) 3 papers published in 2010/2011 (BOEHM, CLENNON), b) further publications planned in the area of "The history of music halls in Cheshire", "Impact Measurement of Community Arts Projects" , "The use of music technology and heritage as drivers of community cohesion"

- The project directly engaged with 2 social enterprises (Wishing Well, The Youth Village).

- The project directly engaged with 4 local businesses (Troubadour, Redshift Radio, History Mystery Tours, Crewe Heritage Centre), 2 of which are currently setting up creative apprenticeships to work with our group (Troubadour and Redshift Radio)

- The project worked directly in partnership with 6 schools and colleges from Crewe and Manchester (Monks Coppenhall Primary School, Hungerford Primary School, Wistaston Primary School, Loreto College, Xaverian College, Stockport College)

\section{Our Principal Community Partners}

Although we also worked with a range of partners including; Monks Coppenhall Primary School, Wistaston Green Primary School, the Cheshire Fire Service's RESPECT programme and Youth Village in Manchester, our main community partners with whom we worked the longest were Wishing Well and South Cheshire CLASP.

Wishing Well: Sherborne Youth club

The Wishing Well Project was originally developed by four partners in 1998, Crewe and Nantwich Borough Council, Cheshire County Council, South Cheshire Health authority and Cheshire Healthcare Trust. Aim of the Wishing Well is to improve the health and well-being of local people through the provision of a range of participative activities and learning opportunities identified and requested by the community. This 
resulted in almost 8,000 members of the West End community participating in activities over the 5 years. Additionally involvement of local volunteers and volunteers from the local college and university added valuable opportunities for all involved.

The Director of Wishing Well writes:

The Sherborne Youth club was developed as a result of a consultation exercise delivered by Wishing Well on behalf of Wulvern Housing. The estate was going through the process of regeneration and the housing association wanted to involve the community in the plans in the hope that in turn the community would have pride in the estate where they lived

Our original aim was to consult with only two groups - our already existing drop in group and the after school club but during the process the local youth began to take a real interest in events - so much so that we involved them In the consultation (they had always hung around the premises when the junior club was running and had often called in for a chat and refreshments) we worked with our Wulvern supporter and estate development manager, Jan, to consider the feasibility of setting up the youth club and developing services for young people. We were delighted when shortly after we were given the go ahead to proceed although our premises were limited to what was originally a refurbished older persons' bungalow!

The club took several weeks to establish but it was worth waiting for as young people came in droves either for short visits or to stay for the full session. These casual styled sessions allowed us to begin to understand the issues involved with living on the estate - for most a close knit community taking care of itself but for others not part of that community it was sometimes a very difficult existence and we realised that when youngsters didn't turn up for the youth club it wasn't necessarily because they didn't want to but often because they didn't dare to. Final Evaluation Report

Music and Drama in a Youth club setting

A series of weekly creative sessions were held over the course of a year in the Sherborne Youth club. Over the year we directly worked with 55 young people whose average age was 13 yrs with $5 \%$ of group aged $16-18 \mathrm{yrs}$, all of whom came from disadvantaged backgrounds on the Sherborne Estate. The young people engaged in activities around historical research around Crewe's murders and Crewe's first suffragette (going on a historical tour of Crewe, visiting the Crewe Heritage Centre and The Women's Library in London) leading to the writing of 'heritage' raps and drama sessions exploring the 1890 Crewe murder that was committed by a young person. Student volunteers from Manchester Metropolitan University also led drama sessions, as part of their Community Arts degree and some workshops took place on campus in our theatre spaces. A young person accessed by our taster street dance and MC workshops held at Wishing Well's premises, Jubilee House, also went onto lead the MC the sessions for the 'heritage' rap tracks. Project objectives included accrediting the creative work of the participants with an Arts Awards (Gold and 
Bronze) and using the creative sessions to further the educational aspirations of the participants.

\section{South Cheshire CLASP: Buzzin’}

South Cheshire CLASP offers support and help to those suddenly facing single parenthood; to those who have been a lone parent for a while; to single parents who parent from a distance; and to the children and young people within single parent families. The service of our organisation is based on a Christian ethos, although the support and activities offered are available to all who are part of a single parent family, regardless of their situation, circumstance and faith. South Cheshire CLASP has been a local support organisation since 1998, obtaining charity status in 2002, and works with over 150 families a year, with the help of a dedicated team of part time staff \& volunteers.

Buzzin' is a Drop-in group within South Cheshire CLASP for young people aged between 12-18 yrs living with one parent/carer and was formed in Crewe, as a group in September 2006. It is both valuable and beneficial for young people to have a safe and confidential place/person outside of their immediate family. At Buzzin' there is opportunity to relax and chat, enjoy refreshments, have a game of pool, play board and card games and take part in discussion sessions on topics which can affect young people, such as coming to terms with just living with Mum or Dad, living in a step family situation, being a young carer coping with anger and bullying.

Songwriting in a Youth drop-in setting

A series of weekly creative sessions were held over the course of a year in the Buzzin' Group. Over the year we worked with 23 young people whose average age was 12 yrs with $30 \%$ of group aged 16 - 18yrs, all of whom came from disadvantaged backgrounds from around Crewe and the surrounding areas. The young people took part in historical research about Crewe that included a tour of Victorian Crewe and a later history workshop given by a local historian. The history workshop led to the group writing a ukulele song about Crewe that was played and recorded by the pupils at Wistaston Green Primary. The group also researched Dickens' Signal Man and used some of the emotional themes in the story to write a screen play of their own, whilst exploring their own emotional issues. Project objectives included accrediting the creative work of the participants with an Arts Awards (Gold) and using the creative sessions to explore their emotional issues.

\section{Evidencing Impact}

We chose to use the case example (a short case study) format to evidence impact because the aim of case studies is to provide "an intensive, holistic description and analysis of a single entity, phenomenon or social unit” (Merriam, 1988:16).

The qualitative approach taken in this study fused elements of ethnography and participatory practice due to the embedded nature of the creative activities. We perceived this as a strength because more traditional methods of data collection such 
as the use of questionnaires can often be off putting in a community context (Kay, 2000) and experimental research designs (control groups etc) for measuring wellbeing are often impractical in an inherently transitory community context (Newman et al., 2003). This meant that with our hybrid qualitative methodology of embedded participant-observer research, we focused on generating "authentic" narratives (Seal \& Silverman, 1997) by collecting data from all stakeholder perspectives as recommended by Kay (2000). This was especially important for collecting in depth data from the participants themselves, as in addition to the participant generated evaluative interviews (www.facebook.com/YM4HProject), their views were routinely recorded as part of the data collecting process for each session.

\section{Evaluation Methods}

Following completion of the project, a series of participatory evaluation sessions were conducted by both principal groups. The groups were facilitated in the making of their own films about the project which included interviews and presentations by both the setting staff and the young participants, the highlights of which are posted on the Young Musicians for Heritage Facebook page. The participatory nature of this evaluation process gave the participants ownership of the iterative nature of the filmed interview process (the recording, the editing, the out-takes, the rehearsals for recording and the discussions that did not make the final public edits) and as a result provided an extremely rich data set. The filmed interviews and accompanying material unused in the final edit, explored the development and implementation of activities, perceptions of the impact of activities, and the contribution of the programme to the participants' self esteem and confidence. The filmed interviews/presentations were reviewed by the interviewees for verification. The interview data was analysed thematically to identify cross-cutting issues. The evaluation framework was then used to analyse all the interview and project data and to assess whether objectives had been met.

The workshop leaders collected data from the sessions that included flip charts, Facebook closed group pages used for out of session engagement, session diaries that recorded activities and processes and photographic documentation. The data from the sessions served to give a rich context for the participants' filmed presentations.

The evaluation adhered to ethical principles. Participation was voluntary and everyone was asked for their consent for the both the evaluation process and the embedded research within the project itself. Quotes and reported experiences have been anonymised.

\section{Findings}

This section will present the findings from the evaluation. The first part will examine the delivery of the project and the use of creative methods. The second part will go on to look at identified outcomes and factors influencing implementation. Finally the paper will present findings on the wider impact of the programme and the contribution of arts to well-being. 
The style of creative delivery and engagement was characterised by careful relationship building with the participants and peer mentoring. We thought that if participants could learn how to share their skills with each other, this would build sustainability in the project, as the young people would be able to continue their learning journeys in their groups after the official end of the Young Musicians for Heritage Project.

\section{Sherborne Youth club}

The Director of Wishing Well writes:

When Manchester Metropolitan University approached us with the view to us being partners in a joint bid to the Young Roots Heritage fund we felt it would be perfect for our Sherborne folks as they had little opportunity to get involved with activities outside of school and the estate.

When Ornette [the workshop coordinator] joined us our young people were quite suspicious about the whole events - why would we want to offer them something special? Final Evaluation Report

Relationship building using creative activities

With the above sentiments in mind, we approached the groups with the view towards organically and slowly building a relationship with the participants before conducting any explicit creative sessions around heritage. Our first sessions at the Sherborne Youth club were used to consult the group about its interests which allowed the workshop leader to plan a slow and group needs-led introduction to creative activities. In the first session, the young people at the Sherborne Youth club identified their main interests in CSI (the TV show, Crime Scene Investigation), rapping and dancing. This meant that in the first few sessions the participants interested in CSI were encouraged to write a story about a murder in Crewe train station (the beginnings of a Crewe 'heritage' theme), devising as many CSI type clues in their story as possible (a preamble to studying the 1890 Crewe Murder). These activities culminated in sessions 19 to 22 when MMU community arts students led CSI drama sessions on campus with the young people in the group.

Casually, in between ongoing youth club activities (session 2), the workshop leader also introduced body rhythms, table top drumming and Steve Reich's clapping music (very structured and rhythmic clapping) to some of the interested participants who taught these rhythms to other participants (the beginnings of peer mentoring). This was done in preparation for introducing the group to the loop (beat) generating software programme Fruity Loops.

In subsequent sessions (from session 3 onwards) the workshop leader gradually introduced the music software Fruity Loops by installing it onto the club's laptops and encouraging the participants to explore making their own beats (which represented moods and emotions from the CSI stories that were being written). Participants were also encouraged to show others how to use the software whilst he had conversations 
with them about how they had been earlier in the week (relationship building through 'on the fly' unstructured interviews).

To further prepare the group for more explicit heritage work, in sessions 7 and 13, they visited heritage sites around Crewe: Crewe Hall, the Crewe Heritage Centre and a Crewe Victorian Murder Mystery Tour. These trips were intended to act as inspiration for the young people's creativity and interaction with their local heritage.

\section{Mentoring using creative activities}

This gradual work with Fruity Loops, body/table rhythm work, peer mentoring and heritage visits culminated in Heritage rap sessions that used Fruity Loops to write the beats (and create the moods) and Cubase to record the raps about the sights they had seen and the stories they had been told. These sessions, which started from session 25, were partly led by a local young person accessed from another group of older young people in the project and crystallised the peer mentoring and training process for this group. In the week leading up to session 34, the group visited The Women's Library in London to get further inspiration for their 'heritage' rap about the first Crewe suffragette. The outputs from the sessions also acted as portfolios for Arts Awards accreditation at Bronze and Gold Levels.

\section{Buzzin'}

Relationship building using creative activities

Similarly with Buzzin' the group was consulted about what it wanted to do that was 'Heritage' related. It was easier to frame the initial enquiry around heritage with Buzzin' than it was with Sherborne because there was a larger percentage of young people aged between 16 - 18yrs. Members of the group identified the trains and the railways as interests. In session 2, the workshop leader introduced the group to the Dickens' story, The Signal Man. The group was inspired by the supernatural overtones of the story and set about writing its own modern version, working into the story, social issues that it recognised as being relevant to young people such as homelessness, male suicide and social networking. In sessions 6 (collecting sound recordings from around the centre) 3 and 19 (jamming sessions on the piano with the participants), the workshop leader carefully used music and music technology to provide a safe and creative outlet for the emotions generated by the group from discussions around bullying, personal relationships and family experiences of child abuse.

In sessions 8 and 9, the group visited heritage sites around Crewe. They visited Crewe Hall, the Crewe Heritage Centre and went on a Crewe Victorian Murder Mystery Tour where they mentored the younger participants from the Sherborne group. As with the Sherborne group, these visits were intended to act as inspiration for the young people's creativity and interaction with their local heritage. As a result of these heritage visits, in session 26, the group participated in a history workshop which was given by the tour guide they had met on their tours of Crewe's heritage sites. This workshop gave them material to enable them to write a song about Crewe's heritage in sessions 27 and 28. 
During the course of the project it became clear that the older participants were interested in using the music and heritage related activities of the project as opportunities to acquire leadership and mentoring skills. In sessions 13 and 14, 16, 17, 20, older members of the group were mentored by MMU music students in songwriting and workshop leadership skills. This sub group of older participants wrote a song for the group and had devised teaching strategies it would employ to teach it to the rest of the group. These writing and teaching skills became useful for the writing of their Crewe heritage song in sessions 27 and 28 which was taught to and performed by another group of young people from Wistaston Green Primary School.

The group's mentoring process culminated in the older participants formalising a sub group in session 33, whose function was to advise Buzzin', to recruit new members to the group and to take more responsibility for the activities and learning within the group. This sub group became known as The Heritage Crew and took a leading role in preparing for the next Heritage Lottery youth project, “Talking Heads”.

\section{Identified Outcomes}

Sherborne Youth club

Case Example 1: Gaining Emotional awareness

A worker from the Sherborne Youth club writes:

Eventually Ornette [workshop coordinator] started to introduce workshops around music, rapping and song-writing and that started to break the group up into interested/not so interested. Some of the young people that had originally just looked into the session and left because numbers and characters were too great for them to cope with started to become very interested in the music opportunities - and at that stage I'm not sure whether it was because the music room was 'safer' with less people in it and a 'managed' activity or because they were truly interested in the music.

Eventually our 'shadowy' folks that lacked confidence sidled into the music room at the earliest opportunity and started to write, hesitantly at first, then avidly about lots of issues affecting their lives and the lives of others. Ornette [workshop coordinator] brought along Mike, a local rap artist and writer and between them they helped our young people not only write their songs but record them too - a turning point for the project I felt - even the young people that 'controlled' the estate thought this was really cool and started to attend and record alongside the other more vulnerable young people. What was particularly noticeable at this stage was that the more vulnerable youngsters that had been writing and recording for a while longer held the respect of the newer more challenging individuals from the estate and as a result the 
confidence of the former individuals grew enormously. Final Evaluation Report

The issues about which the participants were writing were generated in session 25 onwards when the group explored the 1890 Crewe Murder where a son murdered his father. The group re-imagined the emotional dynamic between the father and his two sons that might have led to the father's murder. Issues around domestic bullying (physical abuse) were discussed and the group seemed to plot an emotional narrative that sympathised with the sons' plight in terms of the abuse they imagined they might have been facing from their father (although acknowledging that the son's recourse to murder was wrong). This issue-based work took on a new significance when there was a sudden influx of mainly young men to the group as a result of a drugs raid that was carried out on the estate in session 26. The new participants seemed to be really keen to continue exploring the issue of domestic physical abuse between the father and his sons within the creative rap-writing process and seemed genuinely impressed with the material that had already been written by the other (female) participants.

\section{Case Example 2: Enhancing Self esteem}

A worker from the Sherborne Youth club writes at length:

One young person in particular has made huge progress both in her music interests and in her personal life and confidence. She is part of a local family and is one of many children with a mix of true brothers and sisters and step brothers and sisters. Amongst the family set up and the estate she had become almost insignificant and had attended the club spasmodically and often not come through the door due to her lack of confidence. She had few friends on the estate and attended a local high school where again she didn't particularly shine in any subjects.

What the music project proved is that when young people are really interested in a topic - they shine! This young person started to write her own raps and was delighted when she found she could record them too. Every week we could see a growth in her confidence until she actually started to look cool too - experimenting with clothes and wearing accessories that got her noticed such as large glasses and hats. Ornette [workshop coordinator] introduced the Bronze Arts Award to her and she thoroughly enjoyed the process of earning it mainly within the club setting and with his support. She began to play music that she enjoyed on the computer in the main room of the club and would hum along or jig a bit feeling as though she belonged and having an opinion on all sorts of issues - at last. She participated in several trips and became heavily involved in the heritage part of the project including going to the Women's Library in London to research the speeches of a local suffragette, an experience that she wrote about and recorded when back at Sherborne.

This young person started to change at school too and decided she would like to join a performing arts course at the local college upon leaving school aspiring to this encouraged her to work harder at school and aim for the results that she would need to gain access to the course. She didn't quite make it with 
the results but has put things into place with a local training organisation to help her upgrade on maths and English - she is very determined now and has been accepted at college so long as she works on the upgrades.

She is now considered someone to look up to at the club and has started to bring other individuals in to join us - only last week she brought in a 'stepcousin' who had a beautiful voice but was so shy she had to sit under the table before she could sing. Final Evaluation Report

In session 29, this individual began to mentor others in rapping as part of her Bronze Arts Award.

\section{Case Example 3: Finding Anger management Strategies}

In session 19, the workshop coordinator negotiated a form of anger management with a participant known for his angry outbursts. During a drama session, the young person became very agitated because he did not understand the nature of the warm up activity. He was happy to withdraw himself from the activity and with the support of the workshop coordinator reflect on his emotions where he acknowledged that he had issues with anger and that he wanted help to manage his emotions. With the support of the workshop coordinator, he slowly re-engaged himself with the group's activities. In an extremely chaotic session 20, this strategy seemed to be very effective, as the individual used this approach as a form of self regulation and was able to remain connected to the core activities of the evening. In session 23, due to a minor incident, his anger got the better of him and he seemed unable to regulate his behaviour without the intervention of the workshop leader. However, by session 30, he seemed able to engage with the session by showcasing his beat boxing skills without any outbursts of anger despite some challenges he faced from other participants at times. In session 37, this individual was using the Fruity Loops software programme that had been installed on the club's laptops in session 3, as a creative outlet for his emotions, as he created his own loops, analysed them, graphically notated them and showed them to others during a period of self guided learning. It would appear that the creative activities offered by the project complimented the external support he was receiving for his anger issues by providing creative channels within which he could safely explore his emotions and self regulate his behaviour in-session.

\section{Buzzin’}

Case Example 4: Enhancing Self esteem and Confidence around sexual orientation

The issue around adolescent sexuality and youth clubs for LGBTI young people was first discussed in session 5. However, between sessions 14 to 20, during a period of mentoring in music workshop leadership skills, an individual around whom the mentoring sessions were planned, 'came out' confidentially in session 18 as gay/bi sexual to the setting staff, giving his consent for the workshop coordinator to be informed. This seemed significant because even though the group had discussed issues around sexual orientation on many occasions before, he did not 'come out' until during his music workshop skills mentoring sessions with an MMU music student. Although not necessarily causal there would appear to be a significant link 
between an increase in confidence that the mentoring gave him and an increase in confidence around his sexuality because in session 33 he founded the youth sub group The Heritage Crew for the older young people in Buzzin' and by session 42 he openly and confidently discussed his sexuality with the Buzzin' group and supported other group members with their sexuality by offering to take them to a LGBTI youth club called Utopia.

\section{Discussion}

This will section examine the key points from the findings and discuss the implications for practice before discussing the limitations of the study.

Relationship building

A strong theme to emerge from the findings was the need for an extended period of relationship building where the participants and setting staff could develop a sense of local ownership of the project (South, 2006). This was crucial for both the creative and well-being objectives for the project. In the Young Musicians for Heritage Project the relationship building process took the form of organically introducing heritagebased creative activities through the careful alignment with the needs and the interests of the group. This meant that the creative activities were not viewed as add-on activities; they were viewed as part of the fabric of the groups' activities. This seems to be significant because the embedded nature of creative activity within the group gave the participants alternative (creative) outlets for some of the more challenging emotional/social issues they were facing. This is important because this relationship building developed into partnership working between the workshop coordinator and the setting staff, as the participants' creative outlets were fed back to setting staff to better inform their working relationship with the participants, in-session. This was very interesting because at the start of the project the setting staff's pre-existing background knowledge of the participants was crucial in assisting the workshop coordinator in his relationship building process with the participants. However, as a partnership between him and the setting staff developed through the provision of creative activities, new knowledge of the participants was co-generated as alternative contexts for behaviour were emerging as a result of the creative outlets that were embedded in the activities. South (2004:13) echoes this generation of alternative context when she writes that the "arts is [are] unique in terms of creating opportunities for self expression, problem solving and dialogue”.

However, the biggest factor affecting the nature of relationship building and partnership working in this project was time. Due to the year long duration of the Young Musicians for Heritage Project it was possible to give sufficient time over to this process. Insufficient time and resources can often act as barriers to this crucial stage in a project (Health Development Agency, 2000).

\section{Wider impact}

Even though this paper only focused on the well-being outcomes of two groups in the project, Buzzin' and Sherborne Youth club made links to other groups within Young Musicians for Heritage through shared heritage related creative activity. The network 
created by shared heritage seemed to happen in two phases. Firstly, Buzzin' and Sherborne Youth club as geographically distinct communities in Crewe made strong links with each other when they visited Crewe's heritage sites together, where the older members from Buzzin' took a mentoring role with the younger members from the Sherborne Youth club and some young people visited each others settings. Secondly, both Buzzin' and Sherborne Youth club made connections with other groups within the Young Musicians for Heritage Project. Buzzin' wrote a song for the young people at Wistaston Green Primary school, got involved as youth representatives with a local internet radio station working with the project and used their mentoring skills to work with young people at the Crewe sea cadets (a group external to the project). Sherborne Youth club via its young youth leader made connections with the community organisation, The Youth Village in Manchester by working alongside young people in that community. The building of a social network in the project would seem to suggest that the arts can work powerfully to connect areas of disadvantage, whilst engaging young people and other communities who are usually marginalised (Kay, 2000; Health Development Agency, 2000), although it is difficult to measure the well-being outcomes of these extended connections.

Matarasso (1997) recognises that individuals and communities seem to be strongly linked, as Green and Tones (2003:240) write about the 'mutually reinforcing way' that the arts can both influence individual empowerment (as reported by increased self esteem, self efficacy etc.) and community empowerment (increased networks and social connectedness). This point of individual/community interconnectedness was illustrated during the participatory evaluation process where the setting staff at the Sherborne Youth club were eager to stress that the way in which their group was presented in this paper and to the larger community was important to the collective self esteem of that community. Although during the project, the successful partnership working between the setting staff and workshop coordinator enabled them to face many challenging community issues, the staff at the Sherborne Youth Club wanted to stress the positive outcomes of the project and its processes for fear of diminishing the gains made in the self esteem of the wider Sherborne community to which Young Musicians for Heritage project contributed. These concerns would seem to suggest that the setting staff recognised an important increase in the wider community self esteem, in part generated by the project and that it was important to protect it at all costs.

\section{Limitations of the Study}

It has been acknowledged by Angus (2002) and Hamilton et al. (2003) that there is a lack of good quality evaluations in the area of arts and health, mainly, according to Angus (2002) due to the poorly set out aims and objectives of the projects. However, in this study not only were the aims and objectives clearly set out (as they needed to be for the original bid), they were constantly being updated and informed by the close partnership working between the setting staff and the workshop coordinator, leading to systematic and focused data collection and analysis. The limitations of this study arise from the lack of assessment of long term change as social and learning outcomes from creative activities can often be transitory (South, 2006). We also acknowledge that it is very difficult to distinguish between well-being outcomes generated by the project and those generated externally (Smith, 2001). 


\section{Conclusion}

The sustainability of good practice and the demonstrable well-being outcomes from the project are key. South (2006) describes the general need for the networking and training of local practitioners to continue to work alongside service providers. Whereas we would agree with that in principle, we think that it is important to embed that potential resource in the project from the very beginning. With this in mind, we put a heavy emphasis on peer mentoring and leadership skill training within the groups we worked with using the expertise of our students. This not only promoted group ownership of the project bringing about the already identified well-being outcomes, but also planted the seeds of self determination for the groups as illustrated by the emergence of the youth leadership group, The Heritage Crew and the young youth leader working at the Sherborne Youth club who continued to deliver music provision after the official end of the project. We also hope that the strong partnership working between the workshop coordinator and the setting staff would also sow seeds of empowered practice for the staff, as they have been introduced to the potential of embedded creative working.

Community Arts for well-being can undoubtedly offer new ways of relationship building, partnership working, peer mentoring and self empowerment if sufficient resources are allocated to the process. In our study, we saw that creative methods can be shown to be effective at engaging individuals from disadvantaged backgrounds but also through those individuals, wider communities (Sarkisson \& Wenman, 2010). We would suggest that more longitudinal research is needed to assess the longevity of the well-being outcomes in terms of both individual and community development. Leading on from this, we would also suggest that further studies are carried out to try to distinguish between the well-being outcomes of the creative intervention and that of external factors. We suspect that the two will be inextricably interconnected, prompting us to suggest future research into the nature of their relationship.

\section{Acknowledgements}

We would like to thank all the setting staff and participants of both Sherborne Youth club and Buzzin' drop-in for their support and incredible insight into the process of community development and its impact on well-being. 


\section{References}

Angus, J. (2002), A Review of Evaluation in Community-Based Art for Health Activity in the UK, Health Development Agency, London

Angus, J. (1999), An Enquiry Concerning Possible Methods for Evaluating Arts for Health Projects, Centre for Arts and Humanities in Health and Medicine, Durham

Central Research Unit Scottish Executive (2000), The Role of Arts in Regeneration, The Scottish Arts Council, Scottish Executive: Edinburgh.

Corbin, J., Strauss, A. (1990), Grounded Theory research: procedures, canons and evaluative criteria. Qualitative Sociology, Vol. 13 (1) pp.3 - 21.

Everitt, A., Hamilton, R. (2003), Arts, Health and Community: A Study of Five Arts in Community Health Projects, Centre for Arts and Humanities in Health and Medicine, Durham

Hamilton, C., Hinks, S., Petticrew, M. (2003), Arts for health: still searching for the Holy Grail. Journal of Epidemiology and Community Health, Vol. 57 pp.401-2.

Green, J., Tones, K. (2003), “The creative arts and empowerment” In Dooher, J., Byrt, R. (eds.). Empowerment and the Health Service User Quay Books, Dinton, Vol. Vol. 2 pp.230-47.

Goodlad, R., Hamilton, C., Taylor, D. (2002), Not Just a Treat: Arts and Social Inclusion: Summary Report, University of Glasgow, Glasgow

Health Development Agency (2000), Arts for Health. A Review of Good Practice in Community-Based Arts Projects and Initiatives which Impact on Health and WellBeing, Health Development Agency, London

Kagan, C. and Duggan, K. (2011), Creating Community Cohesion. The power of using innovative methods to facilitate engagement and genuine partnership. Social Policy and Society, 10 (3), pp.393-404.

Kay, A. (2000), Art and community development: the role of the arts have in regenerating communities. Community Development Journal, Vol. 35 No.4, pp.41424.

Kilroy, A., Garner, C., Parkinson, C., Kagan, C. and Senior, P. (2007), Towards Transformation: Exploring the impact of culture, creativity and the arts on health and wellbeing. A consultation report for the Critical Friends event. Manchester, Arts for Health/RIHSC

Landry, C., Matarasso, C. (1996), The Art of Regeneration: Urban Renewal Through Cultural Activity, Joseph Rowntree Foundation, York, Social Policy Summary 8 
Lawthom, R., Kagan, C., Richards, M., Sixsmith, J., Woolrych, R. (2011), “Being Creative: engaging and participative methodologies in critical community psychology arts for public health”. In S. Johnson and C. Horrocks (eds.). Advances in Critical Health Psychology, Basingstoke, Palgrave

Matarasso, C. (1997), Use or Ornament? The Social Impact of Participation in the Arts, Comedia, Stroud

Merriam, S.B. (1988), Case study research in education. San Francisco, CA, JooseyBass

Newman, T., Curtis, K., Stephens, J. (2003), Do community-based arts projects result in social gains? A review of the literature. Community Development Journal, Vol. 38 No.4, pp.310-22.

New Opportunities Fund (2006), Annual Report and Accounts and Policy Directions 2006 Part 3, available at: www.nof.org.uk (accessed 28 June 2012)

Policy Action Team 10 (1999), Arts and Sport: A Report to the Social Exclusion Unit, Department of Culture Media and Sport, London

Sarkisson, W. and Wenman, C. (2010), Creative Community Planning: Transformative Engagement Methods for Working at the Edge - Tools for Community Planning, London: Earthscan.

Seale, C., Silverman, D. (1997), Ensuring rigour in qualitative research, European Journal of Public Health, Vol. 7 pp.79-384.

Sixsmith, J. and Kagan, C. (2005), Pathways Project evaluation: Final Report. Manchester, RIHSC. ISBN 1900139375

South, J. (2006), Community arts for health: an evaluation of a district programme. Health Education, Vol. 106 Iss: 2, pp.155 - 168

South, J. (2004), Community-based arts for Health: A literature review. Centre for Health Promotion Research, Leeds Metropolitan University

Smith, T. (2001), Common Knowledge: The Tyne and Wear Health Action Zone's Arts and Health Project: Interim Evaluation Report, Centre for Arts and Humanities in Health and Medicine, Durham

White, M., Robson, M. (2003), From ice to fire: arts in health for social exclusion, Centre for Arts and Humanities in Health and Medicine, Durham, available at: www.durham.ac.uk/cahhm (accessed 28 June 2012) 